\title{
Two rare manifestations of primary hyperparathyroidism: paralysis and peptic ulcer bleeding
}

\author{
Maryam Heidarpour, Mehdi Karami, Pegah Hedayat and Ashraf Aminorroaya
}

Correspondence should be addressed

Isfahan University of Medical Sciences Isfahan Endocrine and Metabolism Research Center Ringgold Standard Institution, Isfahan, Iran

\section{Summary}

Primary hyperparathyroidism revealed by thoracic spine brown tumor and peptic ulcer bleeding is rare. We presented a case of 33-year-old male patient who was admitted with paraplegia. Thoracic spine magnetic resonance imaging (MRI) showed extradural lesion at T4 level. He underwent surgical decompression in T4. According to histopathologic finding and elevated serum parathormone (PTH) and hypercalcemia (total serum calcium $12.1 \mathrm{mg} / \mathrm{dL}$ ), the diagnosis of brown tumor was down. Ultrasonography of his neck showed a well-defined lesion of $26 \times 14 \times 6 \mathrm{~mm}$. The day after surgery, he experienced 2 episodes of melena. Bedside upper gastrointestinal endoscopy showed gastric peptic ulcer with visible vessel. Treatment with intragastric local instillation of epinephrine and argon plasma coagulation was done to stop bleeding. After stabilization of the patient, parathyroidectomy was performed. Histologic study showed the parathyroid adenoma without any manifestation of malignancy. At discharge, serum calcium was normal ( $8.6 \mathrm{mg} / \mathrm{dL})$. On 40 th day of discharge, standing and walking status was normal.

\section{Learning points:}

- Thoracic spine involvement is a very rare presentation of primary hyperparathyroidism.

- The issue of whether primary hyperparathyroidism increases the risk of peptic ulcer disease remains controversial. However, gastrointestinal involvement has been reported in association with classic severe primary hyperparathyroidism.

- The treatment of brown tumor varies from case to case.

\section{Background}

Brown tumor (also called 'osteoclastoma') is a benign lytic bone lesion due to primary or secondary hyperparathyroidism. Brown color of this tumor is due to the accumulation of osteoclast, blood and fibrous tissue (1). It is found in up to $3 \%$ of hyperparathyroidism (2). This tumor-like lesion may be presented as a solitary or multiple mass that involve bone and adjacent tissues. It rarely locates in the spine (1). To our best knowledge, the case reports of thoracic spine brown tumor due to primary hyperparathyroidism were very rare. Spinal involvement by brown tumor occasionally causes acute neurological deterioration (3). We present a case of paralysis due to brown tumor involving the thoracic spine in a patient with primary hyperparathyroidism.

\section{Case report}

A 33-year-old man referred to our hospital complaining of sudden-onset and progressive weakness of lower extremity within 7 days of admission. He was suffering from thoracic 
back pain for 3 months without any specific medical investigation such as NSAIDs or steroids. His past medical history was significant for intermittent constipation without any symptoms of renal stone, polyuria and polydipsia. On physical examination, he had hypoesthesia below T10 sensory level. In the emergency ward transvers myelitis was suspected, therefore, empiric corticosteroid (methylprednisolone $1 \mathrm{~g}$ single IV dose) was started, and MRI of the brain and spine was done. Brain MRI was normal but thoracic spine MRI showed extradural lesion at T4 level. It was an expansive bone lesion in pedicle of $\mathrm{T} 4$ with extension to right transverse process and lamina with posterior pressure effect on the thecal sac. There was low signal in T1W and high signal in $\mathrm{T} 2 \mathrm{~W}$ images with post contrast enhancement (Fig. 1A, B and C). Due to MRI findings, the differential diagnosis was hemangioma, aneurismal bone cyst and osteoblastoma. The patient was scheduled for surgical decompression. Laboratory values were notable for calcium $12.1 \mathrm{mg} / \mathrm{dL} \quad(8.4-10.2 \mathrm{mg} / \mathrm{dL})$, phosphorus $2.2 \mathrm{mmol} / \mathrm{L}$ (2.7-4.5 mmol/L), magnesium $2.3 \mathrm{mg} / \mathrm{dL}(1.7-2.4 \mathrm{mg} / \mathrm{dL})$, serum 25(OH)vit D $10.6 \mathrm{ng} / \mathrm{mL}$ (30-100 ng/mL), albumin $4.4 \mathrm{~g} / \mathrm{dL}$ (3.5-5.5 g/dL), PTH concentration $1185 \mathrm{pg} / \mathrm{mL}$ (normal: $30-70 \mathrm{pg} / \mathrm{mL}$ ), alkaline phosphatase $403 \mathrm{IU} / \mathrm{L}$ (normal: 100-270IU/L) and hemoglobin was $14.3 \mathrm{~g} / \mathrm{dL}$ (normal: $13.5-17 \mathrm{~g} / \mathrm{dL}$ ). After adequate hydration and administration, calcitonin (200IU intravenously every $6 \mathrm{~h}$ ) surgery was performed in the next day. The mass lesion was removed successfully. Grossly the mass was homogenous, friable and reddish brown mass. Histopathological examination of the lesion showed bone mass with giant cell, osteoblastic and osteoclastic areas, and collagenized stroma consisting of spindle-like mononuclear cell with deposition of hemosiderin (Fig. 2A and B). The first day after surgery, patient reported improvement in the lower extremity power and movement. He was encouraged to stand and sit within the next day. The laboratory data confirmed the diagnosis of primary hyperparathyroidism. Ultrasonography of neck showed a well-defined lesion behind the right lower lobe of the thyroid gland. The plan was parathyroidectomy, however, in the next day, the patient experienced 2 episodes of melena and hemoglobin dropped to $8.3 \mathrm{~g} / \mathrm{dL}$. Therefore, a bedside upper gastrointestinal endoscopy was performed, revealing gastric peptic ulcer with visible vessel localized near the angularis incisura on the lesser curvature. An intragastric local instillation of epinephrine and argon plasma coagulation was done to stop bleeding, and he was admitted to intensive care unit. Therefore, we postpone the parathyroidectomy and cinacalset $30 \mathrm{mg}$ orally once daily was administered.
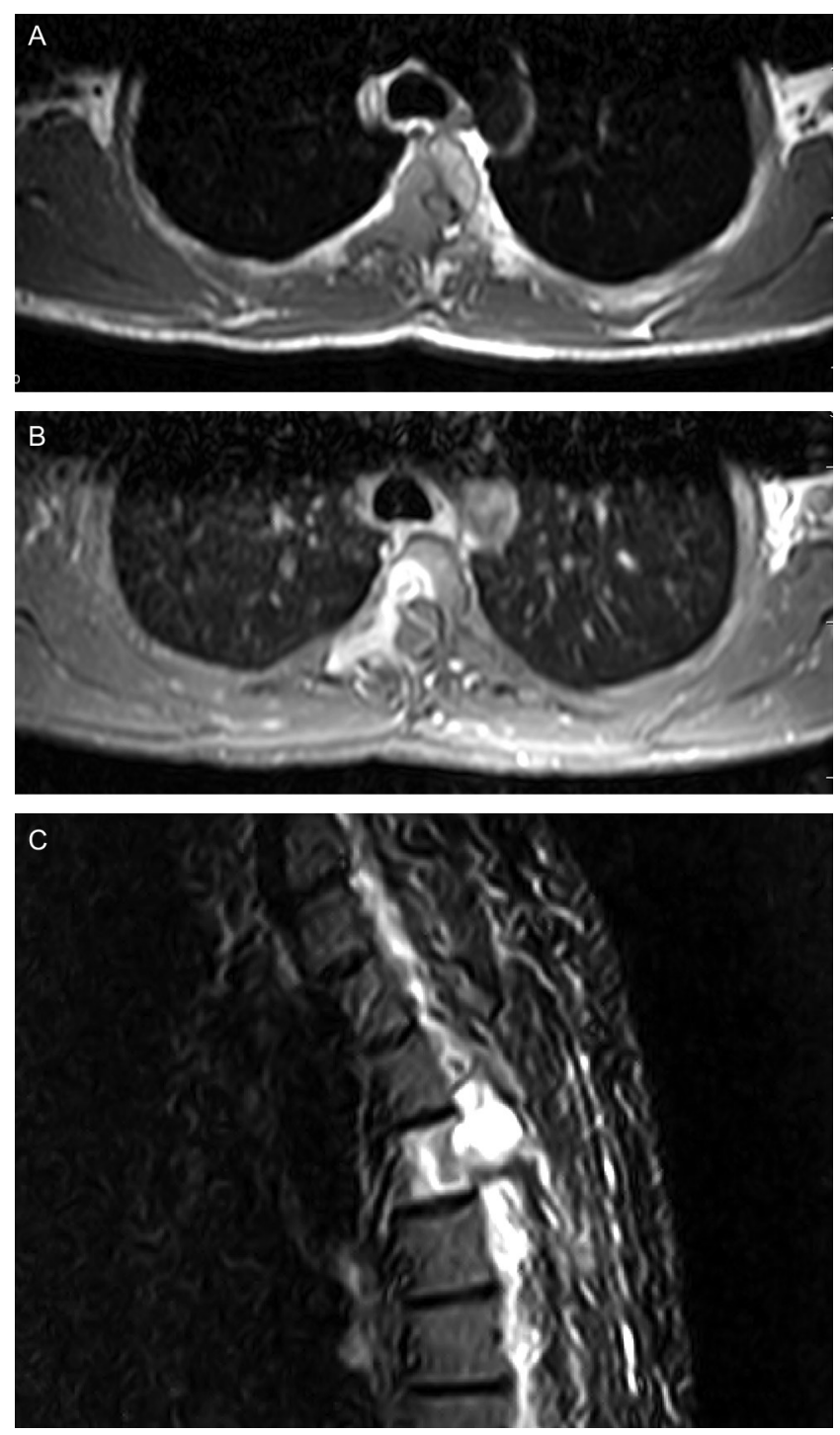

Figure 1

MRI with and without contrast of thoracic spine. Axial (A, B) and sagittal (C) showing expansive bony lesion in pedicle of T4 with extension to right transverse process and lamina with posterior pressure effect on the thecal sac. Low signal in T1W and high signal in T2W images with post contrast enhancement.

After hemodynamic stabilization, resection of parathyroid adenoma was performed in about 20 days later. No clinical and biochemical presentations of hungry bone was observed. Laboratory value was notable for calcium: $9.1 \mathrm{mg} / \mathrm{dL}$, phosphorus: $2.5 \mathrm{mmol} / \mathrm{L}$ and magnesium: $2 \mathrm{mg} / \mathrm{dL}$ on day 1 post surgery. Histological study showed the parathyroid adenoma $26 \times 14 \times 6 \mathrm{~mm}$ without any manifestation of malignancy (Fig. 3). At discharge, there was dramatic improvement in neurological symptoms. His standing and walking status was normal. The laboratory data were in normal range: calcium: $8.7 \mathrm{mg} / \mathrm{dL}(8.4-10.2 \mathrm{mg} / \mathrm{dL})$, 

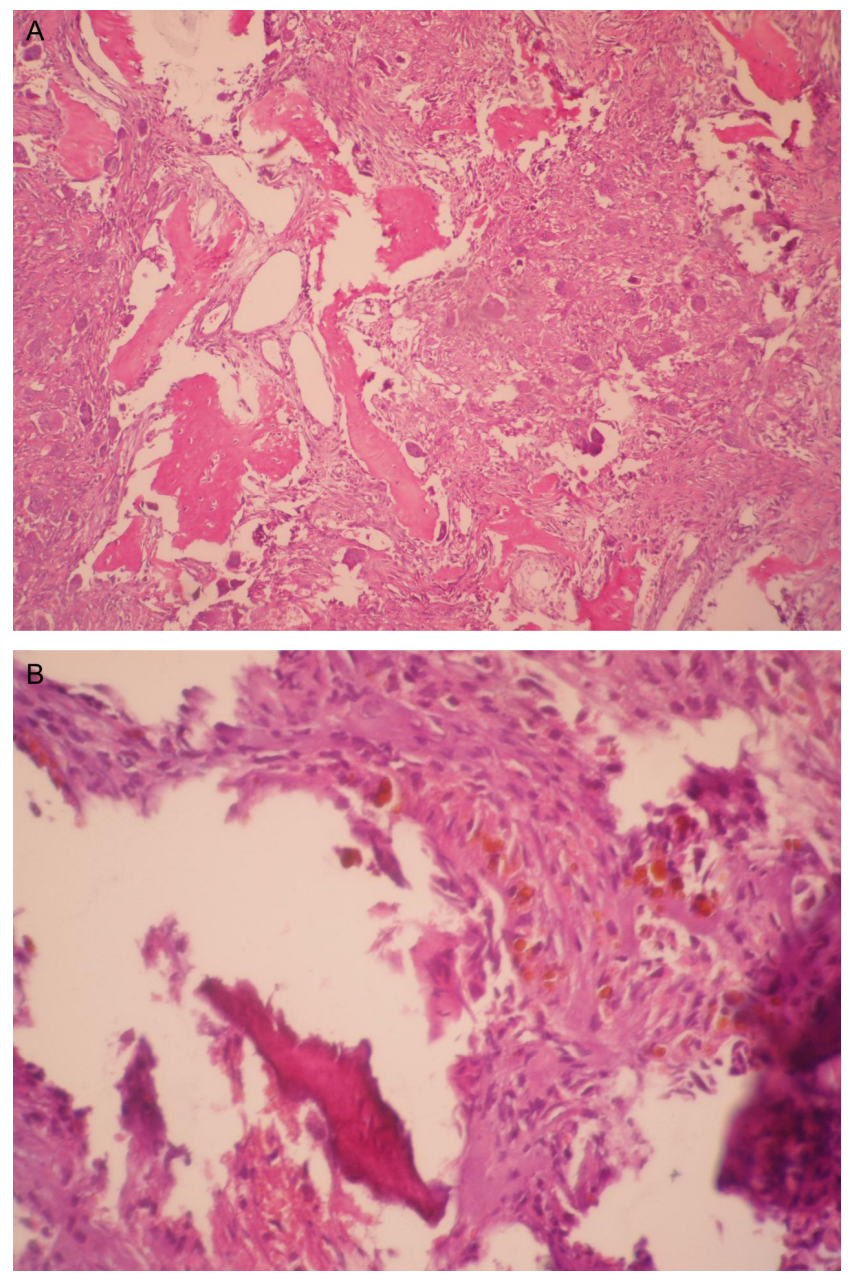

Figure 2

Immunohistochemical study of the thoracic spine mass.

(A) Hematoxyline-eosin staining showing a lots of multinucleated giant cells separated by spindle-shaped mononuclear cells ( $\times 100$ magnification). (B) Hematoxyline-eosin staining hemosiderin deposition in favor of diagnosis of brown tumor ( $\times 400$ magnification).

phosphorus: $2.7 \mathrm{mmol} / \mathrm{L}(2.7-4.5 \mathrm{mmol} / \mathrm{L})$, magnesium: $2.2 \mathrm{mg} / \mathrm{dL}$ (1.7-2.4 mg/dL), albumin: $4.5 \mathrm{~g} / \mathrm{dL}(3.5-5.5 \mathrm{~g} / \mathrm{dL})$ and hemoglobin: $10.1 \mathrm{~g} / \mathrm{dL}$. Therefore, we prescribed daily calcium, vitamin $\mathrm{D}$, iron supplements and pantoprazole $40 \mathrm{mg}$ once daily. Postoperative course was without any adverse event. Patient was followed up at an outpatient on regular bases. On the 40th day of discharge, standing and walking status was normal.

\section{Discussion}

Brown tumor is a focal lytic bone lesion that can be the first manifestation of primary or secondary hyperparathyroidism (3). Nowadays, according to the earlier diagnosis and effective treatment of hyperparathyroidism, it is a rare manifestation in these patients (4). Today, brown tumor is frequently seen in secondary than primary hyperparathyroidism because of increasing prevalence and life expectancy of patients who require hemodialysis. Primary hyperparathyroidism is the third most common clinical endocrine disorder after diabetes and thyroid disease. The most common cause of primary hyperparathyroidism is a solitary parathyroid adenoma, similar to our report (5). In the hyperparathyroidism, classic bone lesions are bone cyst, bone resorption, brown tumor and generalized osteopenia that is supposed to be observed in up to $5 \%$ of patients (6). Brown tumor is a late manifestation of hyperparathyroidism. The histological findings of the brown tumor are similar to those of aneurysmal bone cyst or giant cell tumor. Therefore, the clinical manifestation and the laboratory data should be considered carefully for correct diagnosis. The increased PTH concentration is determinant in correct diagnosis (7). Brown tumor can occur in any bone, most often in the pelvis, ribs, clavicle, sternum, facial bone and extremities (5). Involvement of the spine is very rare but it seems that spinal brown tumor in patients with primary aneurysmal bone cyst usually involve thoracic followed by lumbosacral and then cervical spine (3). If brown tumor has pressure effect on the spinal column, it can cause either slowly progressive symptom or acute spinal cord compression, producing paraplegia or paresthesia. In evaluation of 23 cases with spinal brown tumor (between 1977 and 2011), 15 had evidence of spinal cord compression with paraplegia or paresthesia (8). In X-ray, brown tumor is seen as expansile lytic lesion that is mostly well defined. The cortex may be thinned or fractured. There are few lesions that are osteolytic on X-ray and that show a short T2 on MRI, such as brown tumor (4). The CT scan demonstrates almost well-defined, soft tissue mass with local bone erosion and expansion and shows contrast enhancement, but these finding are not specific, and metastases may have a same appearance (3). MRI is very helpful in the localization and determination of the extent of the spinal involvement. Usually brown tumor exhibits low signal intensity on T1-weighted images, hyper- or hypo intense on T2-weighted images and strong enhancement due to rich vascularity. Repeated intratumoral hemorrhage leads to fluid - fluid level appearance on T2-weighted images (3). There is some controversial issue about the association of hyperparathyroidism and peptic ulcer. The fact is that less than $15 \%$ of patients with primary hyperparathyroidism have symptoms of peptic ulcer, and these symptoms can be relieved after treatment of hyperparathyroidism. 


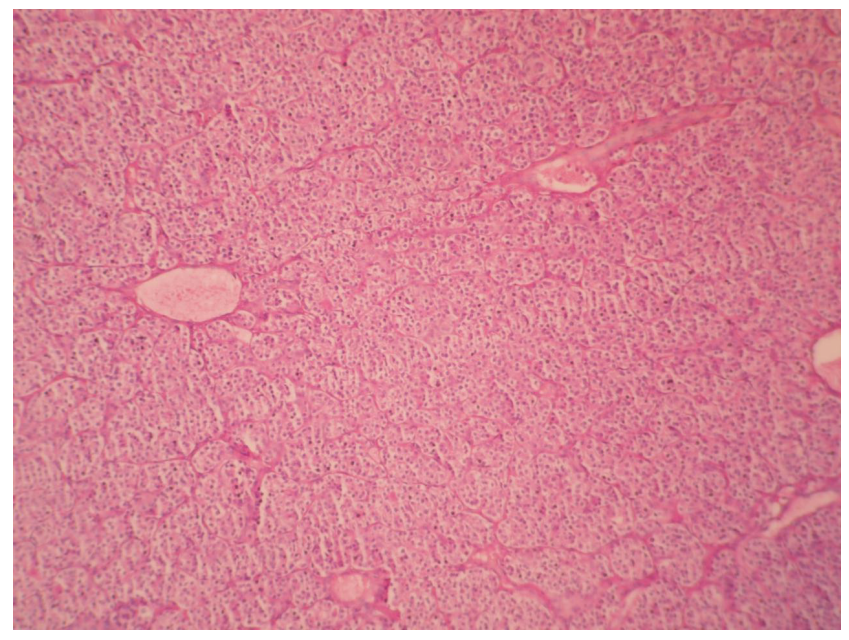

Figure 3

Immunohistochemical study of the parathyroid mass. Hematoxyline-eosin staining showing parathyroid adenoma with chief cell predominance and well vascularization ( $\times 100$ magnification).

Peptic ulcer bleeding due to primary hyperparathyroidism is rare (9). Hypocalcemia is a common problem after parathyroidectomy. It is primarily due to functional or relative hypoparathyroidism. The hypocalcemia is generally transient because the parathyroid tissue recovers function quickly (usually within one week), even after long-term suppression. In some cases, however, the postoperative hypocalcemia is severe and prolonged. This phenomenon, called the hungry bone syndrome, most often occurs in patients who have developed bone disease preoperatively due to a chronic increase in bone resorption induced by high levels of PTH. In a report of 198 patients who underwent parathyroidectomy for primary hyperparathyroidism, it was considered present if the calcium was below $8.5 \mathrm{mg} / \mathrm{dL}$ and phosphate was below $3.0 \mathrm{mg} / \mathrm{dL}$ on the third postoperative day. In this report, elevated preoperative alkaline phosphatase concentration and older age were identified as predictive factors for the development of hungry bone syndrome (10). In our estimation, maybe since the patient was young and the concentration of preoperative alkaline phosphatase was not significantly high, he was not affected by this complication. The treatment of brown tumor varies from case to case. However, the treatment of choice in a patient with primary hyperparathyroidism is most commonly surgical excision of offending parathyroid glands. In spinal involvement, the neurological situation is very important to determine the treatment strategy. Emergency decompression can be mandatory for achieving good results as in our presented case. Management of hyperparathyroidism (usually excision of offending adenoma) is the cornerstone of management of such patients regardless of surgery or conservative approaches for brown tumor. Medical management and parathyroidectomy may be used together (4). Close follow-up after treatment for hyperparathyroidism is important (3).

\section{Conclusion}

We presented a patient with primary hyperparathyroidism manifested by paraplegia due to thoracic spine brown tumor and peptic ulcer bleeding.

\section{Declaration of interest}

The authors declare that there is no conflict of interest that could be perceived as prejudicing the impartiality of the research reported.

\section{Funding}

This research did not receive any specific grant from any funding agency in the pubic, commercial or not-for-profit sector.

\section{Patient consent}

Informed consent was obtained from the patient for publication of the submitted article.

\section{Author contribution statement}

M Heidarpour contributed to the patient care, literature review and manuscript writing. M Karami and P Hedayat provided the MRI report and histopathologic report respectively. A Aminorroaya contributed toward patient care and finalizing the draft of the manuscript.

\section{References}

1 Vandenbussche E, Schmider L, Mutschler C, Man M, Jacquot C \& Augereau B 2004 Brown tumor of the spine and progressive paraplegia in a hemodialysis patient. Spine 29 E251-E255. (doi:10.1097/ 01.BRS.0000127187.58944.FA)

2 Grégoire C, Soussan M, Dumuis ML, Naggara N, Martin A, Dhote R, audard V, Neuman A \& Weinmann P 2012 Contribution of multimodality imaging for positive and etiological diagnosis of multiple brown tumors. Annales d'endocrinologie's 73 43-50. (doi:10.1016/j.ando.2011.10.002)

3 Khalatbari MR \& Moharamzad Y 2014 Brown tumor of the spine in patients with primary HPT. Spine 39 1073-1079. (doi:10.1097/ BRS.0000000000000455)

4 Hong WS, Sung MS, Chun KA, Kim JY, Park SW, Lee KH, Lim HW, Lim YS, Yoo WJ \& Chung MH 2011 Emphasis on the MR imaging finding of brown tumor: a report of five cases. Skeletal Radiology $\mathbf{4 0}$ 205-213. (doi:10.1007/s00256-010-0979-0)

5 Madkhali T, Alhefdhi A, Chen H \& Elfenbein D 2016 Primary hyperparathyroidism. Ulusal Travma ve Acil Cerrahi Dergisi 32 58-66. (doi:10.5152/UCD.2015.3032) 
Endocrinology

Diabetes \& Metabolism

CASE REPORTS
M Heidarpour and others

Brown tumor causing paralysis and GI bleeding
ID: 17-0059; July 2017

DOI: 10.1530/EDM-17-0059
6 Mustonen AO, Kiuru MJ, Stahls A, Bohling T, Kivioja A \& Koskinen S 2004 Radicular lower extremity pain as the first symptom of primary HPT. Skeletal Radiology 33 467-472. (doi:10.1007/ s00256-004-0803-9)

7 Khaoula BA, Kaouther BA, Ines C, Sami T, Zakraoui L \& Khedher A 2011 An unusual presentation of primary hyperparathyroidism: pathological fracture. Case Reports in Orthopedics Article ID: 5215783. (doi:10.1155/2011/521578)

8 Mateo L, Massuet A, Solà M, Andrés R, Musulen E \& Torres M 2011 Brown tumor of the cervical spine: a case report and review of the literature. Clinical Rheumatology 30 419-424. (doi:10.1007/ s10067-010-1608-y)

9 Efremidou E, Liratzopoulos N, Papageorgiou M, Karanikas M, Pavlidou E, Romanidis K \& Manolas K 2007 Peptic ulcer perforation as the first manifestation of previously unknown primary hyperparathyroidism. Case Reports in Gastroenterology $121-26$. (doi:10.1159/000104224)

10 Brasier AR \& Nussbaum SR 1988 Hungry bone syndrome: clinical and biochemical predictors of its occurrence after parathyroid surgery. American Journal of Medicine 84 654. (doi:10.1016/0002-9343(88)90100-3)

Received in final form 4 June 2017

Accepted 22 June 2017 